\title{
ASSOCIATION OF HYPOVITAMINOSIS D AND INSULIN RESISTANCE IN POLYCYSTIC OVARY SYNDROME
}

Vidya A. Gaikwad ${ }^{1}$, Hemant Deshpande ${ }^{2}$, Dhanya Menon ${ }^{3}$

1 Professor and HOU, Department of Obstetrics and Gynaecology, Dr. D. Y. Patil Medical College, Pimpri, Pune.

2 Professor and HOD, Department of Obstetrics and Gynaecology, Dr. D. Y. Patil Medical College, Pimpri, Pune.

$3^{3}$ rd Year Junior Resident, Department of Obstetrics and Gynaecology, Dr. D. Y. Patil Medical College, Pimpri, Pune.

\begin{abstract}
\section{BACKGROUND}

Polycystic ovary syndrome (PCOS) is the most common endocrine disorder in women of reproductive age. PCOS is characterised by the presence of polycystic ovaries, menstrual dysfunction, infertility and biochemical and clinical hyperandrogenism. Vitamin $\mathrm{D}$ deficiency is common in women with PCOS, with the $67-85 \%$ of them having serum concentrations of 25 -hydroxy vitamin D $<20$ $\mathrm{ng} / \mathrm{mL}$. There is increased incidence of cardiovascular disease risk factors, including an increased prevalence of subclinical atherosclerosis, type 2 diabetes, dyslipidaemia, impaired glucose tolerance, obesity and insulin resistance which are closely linked to PCOS and the current obesity epidemic suggests the prevalence of PCOS will rise in future.

The aim of this study was to detect hypovitaminosis D and metabolic syndrome in patients of PCOS. The study was further aimed to detect favourable reproductive outcome in terms of ovulatory cycles and menstrual cycle regularity after supplementation with vitamin D.
\end{abstract}

\section{MATERIALS AND METHODS}

The study was conducted on 49 PCOS women of reproductive age diagnosed by Rotterdam's criteria. The serum vitamin D levels, fasting insulin levels, markers of insulin resistance, markers for metabolic syndrome was noted. PCOS women with Hypovitaminosis D were supplemented with vitamin D and calcium.

\section{RESULTS}

Hypovitaminosis D was seen in 47 cases (95.9\%), metabolic syndrome in 3 (6.1\%) cases. After supplementation with Vitamin D 10 (20.4\%) conceived and 23 (46.9\%) had their menstrual cycle regularised.

\section{CONCLUSION}

Vitamin D deficiency can be an effective factor in development of PCOS and vitamin D supplementation can play a role in prevention of this condition.

\section{KEYWORDS}

PCOD, Vitamin D Deficiency in PCOD, Insulin Resistance, Vitamin D Supplementation in PCOD.

HOW TO CITE THIS ARTICLE: Gaikwad VA, Deshpande H, Menon D. Association of hypovitaminosis D and insulin resistance in polycystic ovary syndrome. J. Evolution Med. Dent. Sci. 2017;6(13):1015-1018, DOI: 10.14260/Jemds/2017/217

\section{BACKGROUND}

Polycystic ovary syndrome (PCOS) is the most common endocrine disorder in women of reproductive age.[1] PCOS is characterised by the presence of polycystic ovaries, menstrual dysfunction, infertility and biochemical (Elevated androgens) and clinical (hirsutism and/or acne) hyperandrogenism.[2] The Rotterdam Criteria for diagnosis of PCOS require the presence of two of the following: oligo/anovulation, clinical and/or biochemical hyperandrogenism or polycystic ovaries on ultrasound. [3] Although there are limited studies of PCOS in India, the observational studies by endocrinologists, gynaecologists, and dermatologists relate to diverse aspects of PCOS.

Financial or Other, Competing Interest: None.

Submission 06-01-2017, Peer Review 31-01-2017,

Acceptance 06-02-2017, Published 13-02-2017.

Corresponding Author:

Dr. Dhanya Menon,

Dr. D. Y. Patil Medical College Hospital

and Research Centre, Pimpri, Pune.

E-mail: dhanya_menon09@hotmail.com

DOI: $10.14260 /$ jemds $/ 2017 / 217$
Most prevalence studies in India are in hospital set-ups and recently a few studies among adolescents in schools report prevalence of PCOS as $9.13 \%$ to $36 \% .[4,5]$ Observational studies showing lower 250HD levels were associated with insulin resistance, ovulatory and menstrual irregularities, lower pregnancy success, hirsutism, hyperandrogenism, obesity and elevated cardiovascular disease risk factors. Vitamin D deficiency may play a role in exacerbating PCOS, and there may be a place for vitamin D supplementation in the management of this syndrome, but current evidence is limited and additional randomised controlled trials are required to confirm the potential benefits of vitamin D supplementation.[6] Considering all these factors, the aim of this study is to detect hypovitaminosis D and metabolic syndrome in patients of Polycystic Ovarian Syndrome and to detect favourable reproductive outcome in terms of ovulatory cycles and menstrual cycle regularity after supplementation with vitamin D.

\section{MATERIALS AND METHODS}

It was a prospective study conducted on randomly selected newly diagnosed PCOD patients coming to the Gynaecology 
OPD of Padmashree Dr. D. Y. Patil Medical College, Hospital and Research Centre, Pune in 2016. 49 patients of PCOS were included in the study. With prior consent and approval from patient and ethical committee, patients were given a questionnaire which included the information regarding age, height, weight, BMI and waist circumference. It also included information regarding menstrual symptoms like menstrual cycle regularity, oligomenorrhoea, high menstrual bleeding, amenorrhoea, blood pressure measurement, markers of metabolic syndrome and presence of insulin resistance, past history and family history. The information regarding laboratory parameters like vitamin D level, fasting blood sugar level, fasting insulin level and lipid profile were also noted. All patients showing vitamin D levels (25(OH)D) concentrations $\leq 30 \mathrm{ng} / \mathrm{mL}(<75 \mathrm{nmol} / \mathrm{L})$ was noted as low Vitamin D levels. These patients were supplemented with $60000 \mathrm{IU}$ of vitamin D3 once a week for 8 weeks and $500 \mathrm{mg}$ of supplemented calcium was given every day. The patient was assessed every month over a period of six months. Favourable reproductive outcome in terms of menstrual cycle regularity, ovulatory cycles, and pregnancy was noted.

\section{Statistical Analysis}

Data management and analysis was done using Microsoft excel and Epi-info software. The frequency distribution and graph were prepared for the variables. The categorical variables were assessed using Pearson chi-square. The test was considered significant only if the $p$ value comes out to be less than 0.05 .

\section{RESULTS}

\begin{tabular}{|c|c|c|}
\hline Age Group (In years) & Frequency & Percent \\
\hline $16-20$ & 10 & $20.4 \%$ \\
\hline $21-25$ & 28 & $57.1 \%$ \\
\hline $26-30$ & 10 & $20.4 \%$ \\
\hline $36-40$ & 1 & $2.0 \%$ \\
\hline Total & $\mathbf{4 9}$ & $\mathbf{1 0 0 . 0 \%}$ \\
\hline \multicolumn{2}{|c|}{ Table I. Distribution of Cases According to Age Groups } \\
\hline
\end{tabular}

Out of 49 total cases, majority of the PCOS group of patients were aged between 21-25 years, 10 patients were adolescent PCOS (20.4\%).

\begin{tabular}{|c|c|c|}
\hline Vitamin D level & Frequency & Percentage \\
\hline Deficiency $(<20 \mathrm{ng} / \mathrm{mL})$ & 42 & $85.7 \%$ \\
\hline Insufficiency $(20-30 \mathrm{ng} / \mathrm{mL})$ & 5 & $10.2 \%$ \\
\hline Normal (30-100 ng/mL) & 2 & $4.1 \%$ \\
\hline Total & $N=49$ & $100.0 \%$ \\
\hline \multicolumn{3}{|c|}{$\begin{array}{c}\text { Table II. Distribution of Cases According to Vitamin D } \\
\text { Levels }\end{array}$} \\
\hline
\end{tabular}

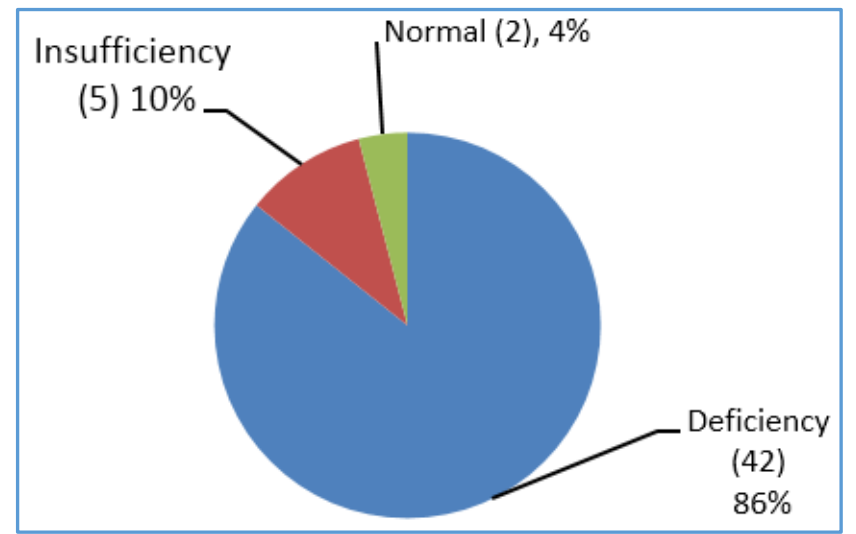

Graph 1

Vitamin D deficiency was found in 42 (85.7\%) cases, insufficiency was found in $5(10.2 \%)$ cases and only $2(4.1 \%)$ cases had normal vitamin $\mathrm{D}$ levels.

\begin{tabular}{|c|c|c|}
\hline Type & Frequency & Percent \\
\hline Obese & 26 & $53.1 \%$ \\
\hline Lean & 23 & $46.9 \%$ \\
\hline Total & 49 & $100.0 \%$ \\
\hline \multicolumn{2}{|c|}{ Table III. Distribution of Cases } \\
According to Type (Obese/Lean) \\
\hline
\end{tabular}

The clustering of central obesity, hypertension, and dyslipidaemia has been termed "the metabolic syndrome."

\begin{tabular}{|c|c|c|}
\hline Markers of Metabolic Syndrome & Frequency & Percent \\
\hline Total no. of cases (N = 49) & 3 & $6.1 \%$ \\
\hline \multicolumn{2}{|c|}{ Table IV. Distribution of Cases According to } \\
Presence of Markers of Metabolic Syndrome \\
\hline
\end{tabular}

\begin{tabular}{|c|c|c|}
\hline Outcome & Frequency & Percent \\
\hline Cycles regularised & 23 & $46.9 \%$ \\
\hline Conceived & 10 & $20.4 \%$ \\
\hline Lost to followup & 4 & $8.2 \%$ \\
\hline Still on treatment & 12 & $26.6 \%$ \\
\hline Total & 49 & $100.0 \%$ \\
\hline \multicolumn{3}{|c|}{$\begin{array}{l}\text { Table V. Distribution of Cases According to } \\
\text { Outcome after Vitamin D Supplementation }\end{array}$} \\
\hline
\end{tabular}

Out of 49 PCOS cases, 10 (20.4\%) conceived after supplementation with Vitamin D, and 23 (46.9\%) had their menstrual cycle regularised after receiving Vitamin D supplementation while 12 patients $(26.6 \%)$ were still on treatment.

\begin{tabular}{|c|c|c|c|c|c|}
\hline Variables & $\mathbf{N}$ & Minimum & Maximum & Mean & $\begin{array}{c}\text { Std. } \\
\text { Deviation }\end{array}$ \\
\hline $\begin{array}{c}\text { BMI }\left(\mathrm{kg} / \mathrm{m}^{2}\right) \\
(18.5-24.9)\end{array}$ & 49 & 20.00 & 36.80 & 26.54 & 5.094 \\
\hline $\begin{array}{c}\text { Waist } \\
\text { Circumference } \\
(\mathrm{cm})<80 \mathrm{~cm}\end{array}$ & 49 & 68.00 & 100.00 & 83.05 & 8.2666 \\
\hline $\begin{array}{c}\text { Fasting } \\
\text { Insulin (2.6- } \\
24.9 \mu \mathrm{H} / \mathrm{mL})\end{array}$ & 49 & 2.00 & 41.44 & 14.8333 & 10.151 \\
\hline $\begin{array}{c}\text { Vitamin D } \\
\text { Levels (30- } \\
100 \mathrm{ng} / \mathrm{mL})\end{array}$ & 49 & 4.2 & 31.49 & 13.34 & 6.269 \\
\hline
\end{tabular}




\begin{tabular}{|c|c|c|c|c|c|}
\hline $\begin{array}{c}\text { Fasting BSL } \\
(70-100 \\
\mathrm{mg} / \mathrm{dL})\end{array}$ & 49 & 72.00 & 112.00 & 87.69 & 8.605 \\
\hline $\begin{array}{c}\text { Serum } \\
\text { Cholesterol } \\
(125-200 \\
\mathrm{mg} / \mathrm{dL})\end{array}$ & 49 & 154.00 & 252.00 & 178.7347 & 18.67795 \\
\hline $\begin{array}{c}\text { HDL (35-80 } \\
\mathrm{mg} / \mathrm{dL})\end{array}$ & 49 & 34.00 & 50.00 & 41.8776 & 4.26044 \\
\hline $\begin{array}{c}\text { LDL (85-130 } \\
\mathrm{mg} / \mathrm{dL})\end{array}$ & 49 & 83.40 & 133.00 & 96.6286 & 10.20817 \\
\hline $\begin{array}{c}\text { Triglycerides } \\
(25-200 \\
\text { mg/dL) }\end{array}$ & 49 & 97.00 & 140.00 & 111.3469 & 10.27244 \\
\hline \multicolumn{7}{|c|}{ Table VI. Mean Values for Various Physical and } \\
Biochemical Indices PCOS Cases \\
\hline
\end{tabular}

\section{DISCUSSION AND CONCLUSION}

Although vitamin D primarily plays a role in bone metabolism, it has important functions in the reproductive system. Vitamin D receptors are found in ovarian and endometrial tissues and play an important role in steroidogenesis. A high prevalence of vitamin D deficiency has been reported all over India for all age groups including neonates, infants, school-going children, adolescents, adults, pregnant and lactating women, and senior citizens. This is probably a result of poor sun exposure, dark skin complexion, atmospheric pollution, vegetarian food habits, absence of food fortification with vitamin $D$, and poor intake of vitamin $D$ supplements. Garg et al did a study in 2015 (India) where [7] Vitamin D deficiency was observed in $93.8 \%$ in all PCOS patients while the rest had vitamin D insufficiency (20-30 $\mathrm{ng} / \mathrm{mL}){ }_{\left[{ }^{[8]}\right.}$ In the present study, out of 49 PCOS cases, vitamin D deficiency was found in $42(85.7 \%)$ cases, insufficiency was found in $5(10.2 \%)$ cases and only $2(4.1 \%)$ cases had normal vitamin D levels. The mean value of vitamin D was 12.9 (4.231.4). In the study conducted by Setenay Arzu Yılmaz,[9] the mean Vitamin D level of the lean PCOS cases was 12.4 (4.146.7) $\mathrm{ng} / \mathrm{mL}$ and mean Vitamin D level of the obese PCOS cases was $10.1(2.5-25.0) \mathrm{ng} / \mathrm{mL}$. In patients with PCOS, vitamin D levels were found to be low, independent of BMI and insulin resistance.[10] Mazloomi S et al in their study have reported low levels of vitamin D in women with PCOS, with average vitamin D (25-OHD) levels between 11-31 ng/mL, and the majority having values $<20 \mathrm{ng} / \mathrm{mL}$ (67-85\%) which is comparable to our study. Apart from other risk factors, PCOS itself was found to be associated with decreased vitamin D levels, which is similar to our study.

In the present study, amongst 49 total cases of PCOS, 23 cases were lean and 26 were obese. Mean age of 49 cases was $23.4 \pm 3.9$ years. Age ranged from 16 years to 40 years. In our study, out of 23 lean PCOS, 18 (78.2\%) had Vitamin D deficiency $[<20 \mathrm{ng} / \mathrm{mL}]$ and $4(17.3 \%)$ had Vitamin D Insufficiency [20-30 ng/mL] and out of 26 obese PCOS 24 (92.3\%) had Vitamin D deficiency and 1(3.8\%) had Vitamin D Insufficiency.

Many studies have reported inverse associations between body weight (BMI, body fat and waist measurements) and serum 25-OHD levels in women with PCOS, with report of levels 27-56\% lower in obese women with PCOS, compared to non-obese women with PCOS. A recent study in women with PCOS also found low 25-OHD levels were significantly determined by the degree of adiposity (BMI and total fat mass) and were not directly affected by the development of insulin resistance.[11] Out of 49 PCOS patients, 3 (6.1\%) patients had markers of metabolic syndrome in the form of raised cholesterol, raised triglycerides, raised LDL, reduced HDL, hypertension, central obesity, raised fasting blood sugar levels in one or more combinations. Kotsa et al showed an improvement of HDL and triglycerides after treatment with vitamin D in a small cohort of PCOS women.[12] Since dyslipidaemia should be considered as an additional therapeutic target in PCOS, vitamin D might be useful in the complex treatment of PCOS women. [13] These parameters, i.e. low HDL and elevated triglycerides, are central features of metabolic syndrome. In our study of 49 PCOS patients, 23 (46.9\%) patients had markers of insulin resistance like acne, hirsutism, acanthosis nigricans.

In patients with vitamin $\mathrm{D}$ deficiency, we had supplemented them with Injection Vitamin D, 6 Lakh IU given intramuscularly, 2 doses 6 weeks apart, and in those with insufficiency oral vitamin D supplementation was given in the form of 60,000 IU, once a week for 8 weeks and thereafter once a month as maintenance. In all these patients, oral calcium $500 \mathrm{mg}$ tablets were also added once daily. In the patients with insulin resistance and obesity, metformin 500 mg tablet was given in oral form. In addition, advice on diet and lifestyle modification was also instructed. Other insulin sensitisers like myo-inositol, D-chiro inositol, berberine were not used in any of these patients.

Out of 49 cases of PCOS, 47 patients (95.9\%) received exclusively vitamin D supplementation and calcium supplementation. We had $45(91.8 \%)$ patients who came for followup and improved in terms of reproductive outcome that is $10(20.4 \%)$ patients conceived and 23 patients (46.9\%) had regular menstrual cycles after treatment. This is a significant observation. Our study can be compared to the study done by Thys-Jacobs $\mathrm{S}$ et al where the aim of their study was to determine whether vitamin D and calcium dysregulation contribute to the development of follicular arrest in women with PCOS, resulting in reproductive and menstrual dysfunction. Vitamin D repletion with calcium therapy resulted in normalised menstrual cycles within 2 months for seven women, with two experiencing resolution of their dysfunctional bleeding. Two became pregnant, and the other four patients maintained normal menstrual cycles.[14]

Thus, Vitamin D deficiency is common in patients of PCOS, both in lean and obese. Supplementation with Vitamin D and Calcium can improve the menstrual disorders associated with PCOS and with a favourable reproductive outcome. However, our study has its limitation in the small sample size. More randomised controlled studies with large number of patients will confirm the potential benefits of Vitamin D supplementation in PCOS patients. In the present study, out of 49 PCOS cases, vitamin D deficiency was found in 42 $(85.7 \%)$ cases, insufficiency was found in $5(10.2 \%)$ cases and only $2(4.1 \%)$ cases had normal vitamin D level and after supplementation 23 (46.9\%) patients had good outcome in terms of menstrual cycle regularisation and 10 (20.4\%) patients conceived which is a significant and positive outcome. We found significant lower levels of absolute serum 
vitamin D or prevalence of vitamin D deficiency among women with PCOS.

\section{CONCLUSION}

The potential relationship between vitamin D and PCOS requires further investigation, since vitamin $\mathrm{D}$ deficiency has been continuously proposed to increase the risk of insulin resistance and T2DM, which is also a core pathophysiology of PCOS. Thus, in conclusion, Vitamin D deficiency can be an effective factor in development of PCOS and vitamin D supplementation can play a role in prevention of this condition. Supplementation of Vitamin D in our cases helped in favourable reproductive outcome in terms of ovulatory cycles, menstrual cycle regularity and conception.

\section{REFERENCES}

[1] Conway G, Dewailly D, Diamanti-Kandarakis E, et al. The polycystic ovary syndrome: a position statement from the European society of endocrinology. Reproductive Endocrinology 2015;25:32-52.

[2] March WA, Moore VM, Willson KJ, et al. The prevalence of polycystic ovary syndrome in a community sample assessed under contrasting diagnostic criteria. Human Reproduction 2010;25(2):544-51.

[3] Rotterdam ES, ASRM-Sponsored PC. Revised 2003 consensus on diagnostic criteria and long-term health risks related to polycystic ovary syndrome. Fertility and sterility 2004;81(1):19-25.

[4] Nidhi R, Padmalatha V, Nagarathna R, et al. Prevalence of polycystic ovarian syndrome in Indian adolescents. J Pediatr Adolesc Gynecol 2011;24(4):223-7.

[5] Nair MK, Pappachan P, Balakrishnan S, et al. Menstrual irregularity and poly cystic ovarian syndrome among adolescent girls: a two year follow-up study. Indian J Pediatr 2012;79(Suppl 1):S69-73.
[6] Krul-Poel YHM, Snackey C, Louwers Y, et al. The role of vitamin $\mathrm{D}$ in metabolic disturbances in polycystic ovary syndrome: a systematic review. European Journal of Endocrinology 2013;169(6):853-65.

[7] Garg G, Kachhawa G, Ramot R, et al. Effect of vitamin D supplementation on insulin kinetics and cardiovascular risk factors in polycystic ovarian syndrome: a pilot study. Endocrine connections 2015;4(2):108-16.

[8] Badawy A, Elnashar A. Treatment options for polycystic ovary syndrome. Int J Womens Health 2011;3(1):25- 35.

[9] Yılmaz SA, Altınkaya SO, Kebabçılar A, et al. The relationship between polycystic ovary syndrome and vitamin D levels. J Turk Soc Obstet Gynecol 2015;1:1824.

[10] Mazloomi S, Sharifi F, Hajihosseini R, et al. Association between hypoadiponectinemia and low serum concentrations of calcium and vitamin D in women with polycystic ovary syndrome. ISRN Endocrinol 2012;2012:949427.

[11] Lagunova Z, Porojnicu AC, Lindberg F, et al. The dependency of vitamin D status on body mass index, gender, age and season. Anticancer Research 2009;29(9):3713-20.

[12] Kotsa K, Yavropoulou MP, Anastasiou 0, et al. Role of vitamin $\mathrm{D}$ treatment in glucose metabolism in polycystic ovary syndrome. Fertility and Sterility 2009;92(3):1053-8.

[13] Diamanti-Kandarakis E, Kandaraki E, Christakou C, et al. The effect of pharmaceutical intervention on lipid profile in polycystic ovary syndrome. Obesity Reviews 2009;10(4):431-41.

[14] Thys-Jacobs S, Donovan D, Papadopoulos A, et al. Vitamin D and calcium dysregulation in the polycystic ovarian syndrome. Steroids 1999;64(6):430-5. 